\title{
Redox Changes in Amateur Race Car Drivers Before and After Racing
}

\section{(ㄷ) (1) (우 $\ominus$}

\author{
Authors \\ Kimberly B. Bjugstad², Paul Gutowski², Jennifer Pekarek², Pamela Bourg², Charles W. Mains², David Bar-Or ${ }^{1}$
}

\section{Affiliations}

1 Swedish Medical Center, Trauma Research, Englewood, United States

2 St. Anthony Hospital, Trauma Research, Lakewood, United States

\section{Key words}

car racing, hypertension, heart rate, antioxidant capacity

$\begin{array}{lr}\text { received } & 22.05 .2017 \\ \text { revised } & 27.07 .2017 \\ \text { accepted } & 17.08 .2017\end{array}$

\section{Bibliography}

DOI https://doi.org/10.1055/s-0043-119065

Sports Medicine International Open 2017; 1: E212-E219

(c) Georg Thieme Verlag KG Stuttgart · New York

ISSN 2367-1890

\section{Correspondence}

Dr. David Bar-Or, MD

Swedish Medical Center, Trauma Research

501 East Hampden Avenue

80113 Englewood

United States

Tel.: + 1/303/788 4089, Fax: +1/303/7884064

dbaror@ampiopharma.com

\begin{abstract}
Despite the unique opportunity race car driving provides to study exercise in extreme conditions, the sport of racing is under-represented. A better understanding of how racing changes physiological measures combined with driver demographics may help reduce driver risks and expand the field of driver science. This study charted the changes in heart rate, body temperature, blood pressure, static oxidation reduction potential (SORP), and antioxidant capacity in drivers before and after racing $(n=23)$. The interaction between racing and driver characteristics on physiological variables were evaluated. Heart rate, body temperature, and sORP were elevated after racing $(\mathrm{P}<0.05)$. Age, cockpit temperature, experience, and speed did not correlate with physiological or oxidative measures $(P>0.05)$. Elevated post-race sORP values were associated with higher pre-race systolic blood pressure and lower antioxidant capacity $(P<0.05)$. We conclude that racing alters the redox response in drivers and that drivers' pre-race systolic blood pressure and antioxidant capacity can further alter it. A better understanding of the physical and oxidative changes which result from racing may help minimize the unique risks
\end{abstract}

\section{Introduction}

The field of driver science has not built the momentum that other fields in sport science have, despite the unique opportunities present in this sport. The unique conditions of car racing - the exertion of driving, cockpit temperatures, and high speeds - produce physiological and cardiovascular stress [48]. There is evidence that drivers experience increased body temperature (up to $38^{\circ} \mathrm{C}$ ) and heart rate $[8,44,47,48]$ but there is a paucity of information about blood pressure [8] and less about the redox response that regulates oxidative stress (OS).

Despite the lack of information on sport racing, there are exercise studies that suggest interactive effects between physiological measures and environmental context. When exposed to hyperther- mic conditions during exercise, body temperature, heart rate, and OS markers increase [18, 26, 39]. Cycling alone induced protein oxidation, but in hyperthermic conditions, lipids were more often oxidized whereas protein oxidation was prevented [39]. Running increases two measures of lipid oxidation, F2-isoprostanes and lipid hydroperoxides, but in hyperthermic conditions, only F2-isoprostanes levels are increased [26]. These studies suggest that there are multiple avenues through which OS can occur depending on the type of exercise and the conditions in which it happens. The combined physical exertion of driving and the unique external features of racing could also alter the redox response resulting in OS.

Redox changes during exercise is gaining attention as an adaptive mechanism $[9,25,26,28,29,39,40,43,44]$. It is associated 
with the activation of the autonomic nervous system [29,45] and, like exercise-induced changes in heart rate and blood pressure, it can have a hormetic effect [28]. Free radicals, such as reactive oxygen species (ROS) and nitric oxide (NO), have physiological roles in vascular tone, immune responses, wound healing, and cell signaling $[3,15,21,28,46]$. However, when there is an excessive or chronic redox imbalance in favor of free radicals, OS occurs causing damage to nearby lipid, proteins, and DNA. OS plays a significant role in the development of cardiovascular and neurological disorders $[2,19,20,38]$.

The presence of OS can be implied by measuring singular or paired biomarkers, such as ascorbic acid, ROS, lipid hydroperoxides, or the ratio of reduced to oxidized glutathione. However, redox imbalance does not necessarily result from the imbalance of a single component. The redox system regulates the production of all oxidants and all antioxidants, thus measuring a single component gives a potentially misinformed view of how the redox system is working. A more global indicator of redox imbalance can be determined by measuring oxidation-reduction potential (ORP), which is a measure of a biological sample's tendency to lose electrons (oxidize) or gain electrons (reduce) regardless of the donating or receiving agent [37]. Thus ORP provides a versatile indicator of how all oxidants and all antioxidants are working. ORP has been used to assess relative $O S$ in many medical conditions $[4,5,7,32,33,37$, $40,41,43,51]$.

Because there is little information regarding OS and car racing, despite the implications for it, we studied the redox status as an indicator of $O S$ in race car drivers and the interactive effects between redox status, other physical measures, and driver demographics.

\section{Materials and Methods}

\section{Institutional approval and consent}

The study was approved by IntegReview Institutional Review Board and was done in accordance with institutional guidelines and those outlined by the International Journal of Sport Medicine [17]. Each driver signed a consent form prior to participation in the study.

\section{Study design}

This was a prospective, observational pre-post study measuring physiological stress pre-race (baseline) and post-race in volunteer drivers. The physiological variables were heart rate, blood pressure, body temperature, and oxidation-reduction potential (ORP). These variables were compared for changes from baseline and between groups. Groupings were based on the use of cooling shirts, daily vitamin use, alcohol use, and hypertension. Secondary variables included driver age, body mass index (BMI; height and weight), years of experience, internal cockpit temperature, and maximum lap speed. Ambient temperature and relative humidity on the day of baseline and race day were recorded and the daily average was used. See $>$ Fig. 1 for timeline of events.

\section{Selection criteria}

Healthy amateur male race car drivers were recruited from the Porsche Club of America (PCA) Rocky Mountain Region's 24th Porsche Club Race (High Plains Raceway, Deer Trail, CO, USA). Consenting males $>18$ years old were included. Females were not included due to lack of significant participation. Consenting drivers were excluded if there was no baseline measure taken at least $24 \mathrm{~h}$ prior to the $3^{\text {rd }}$ practice session or if they failed to race in the $3^{\text {rd }}$ session (See timeline).

\section{Data collection}

Participants filled out a survey about age, BMI, hypertension, daily vitamin use (antioxidants), smoking, and drinking habits. Alcohol use reflected a lifestyle choice; drivers were not drinking during the race event. The survey included years racing, use of cooling shirts, and experience with the current track. After consent baseline measures of heart rate, blood pressure, body temperature, and ORP were obtained. Baseline measures were taken prior to the open lap session on Day 1 so that baseline measures truly reflected pre-racing levels. Open lap sessions are a time when drivers can unofficially practice on the track. Post-race measures were taken after the $3^{\text {rd }}$ practice race about $24 \mathrm{~h}$ later. The $3^{\text {rd }}$ practice race was a qualifying race for the final race (see $>$ Fig. 1 for timeline). We chose to collect data after the $3^{\text {rd }}$ practice to optimize the number of participants, because some drivers would not qualify for the final race and thus would not be able to contribute to post-race data.

Post-race body temperature and cockpit temperature were recorded in the hot pit. Heart rate, blood pressure, and ORP were measured after drivers removed their driving suits. Cockpit temperatures were collected using an infrared laser thermometer gun. Speed data was determined by the fastest lap time officially posted at the raceway. Ambient temperature and humidity were recorded three times on both days.

\section{Physiological measures}

A digital oral thermometer with disposable probe covers was used to obtain body temperatures. Blood pressures and heart rate were obtained within 60 min after coming off the track for post-race measures. Systolic and diastolic blood pressures (sBP and dBP, respectively) were recorded. The radial heart rate was taken manually at the time blood pressures were taken.

\section{Redox status through ORP values}

Redox status was determined electrochemically by measuring oxidation-reduction potential (ORP). ORP was measured on site from freshly obtained whole blood samples using the RedoxSYS System ${ }^{\circledR}$. Using a heparinized vacutainer, one tube of blood was collected after blood pressure and heart rate measures. The RedoxSYS System is comprised of an electrochemical analyzer and single-use, disposable whole-blood sensors (Aytu BioScience, cat. \# 100016 and \#100347, respectively). Fifty microliters $(50 \mu \mathrm{L})$ of whole blood were added to the sensor pre-inserted into the RedoxSYS analyzer. The analyzer begins testing immediately upon sample detection. Data are presented as the static ORP (sORP, millivolts: $\mathrm{mV}$ ) and capacity ORP (cORP, microcoulombs: $\mu \mathrm{C}$ ). sORP is a measure of the current state of OS; a higher SORP value indicates a redox potential in favor of oxidant activity. CORP is a measure of antioxidant capacity; a higher cORP value (lower icORP- see below) indicates an increased capacity to mitigate oxidative insults. Both ORP measures were done in duplicate and averaged. 


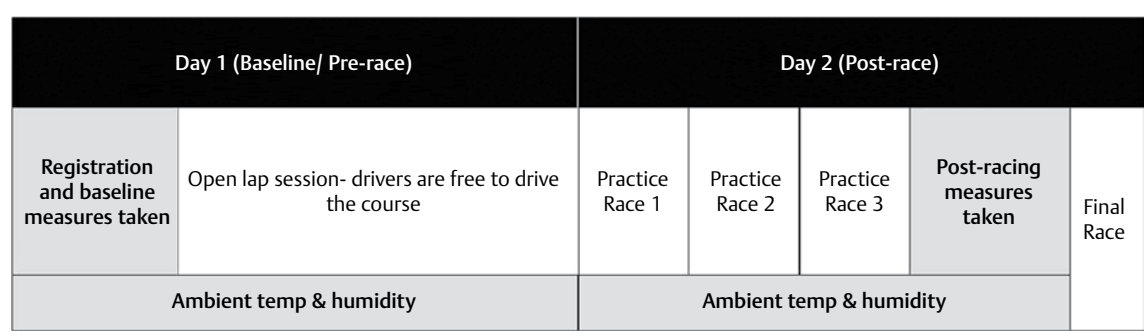

Fig. 1 A timeline of procedures over the course of the 2-day racing event.

- Table 1 Descriptive statistics of drivers and driving conditions.

\begin{tabular}{|c|c|c|c|}
\hline Descriptive Statistics & Median (min-max) & Mean & SEM \\
\hline Age (years) & $59.5(36-76)$ & 59.7 & 2.4 \\
\hline Height $(\mathrm{cm})$ & $177.8(167.6-190.5)$ & 180.0 & 1.4 \\
\hline Weight $(\mathrm{kg})$ & $83.9(65.8-108.9)$ & 83.3 & 2.4 \\
\hline BMI & $25.8(20.8-30.0)$ & 25.8 & 0.53 \\
\hline Years Racing & $15(1-45)$ & 14.8 & 2.2 \\
\hline Internal Car Temp $\left({ }^{\circ} \mathrm{C}\right)$ & $26.1(22.2-37.2)$ & 26.4 & 0.63 \\
\hline Speed (km/hr) & $71.0(67.5-83.2)$ & 72.7 & 0.95 \\
\hline Group Sizes & Yes & No & \\
\hline Cooling Shirt & 11 & 12 & \\
\hline Daily Vitamin Use & 13 & 10 & \\
\hline Alcohol Use & 20 & 3 & \\
\hline Hypertension (HBP Medications) & 7 & 16 & \\
\hline First Time on Track & 2 & 21 & \\
\hline Environmental Conditions & Day 1 & Day 2 & \\
\hline Daily Temperature $\left({ }^{\circ} \mathrm{C}\right)$ & 21.3 & 28.3 & \\
\hline Relative Humidity (\%) & 41.6 & 14.7 & \\
\hline
\end{tabular}

\section{Data analysis}

Data was analyzed using 2-way mixed model ANOVAs (Statistica, Dell Software). Fisher's LSD post-hoc tests were used for significant ANOVA effects $(P<0.05)$. The pre/post-race data was used in all ANOVA analyses as the repeated measure. There were four independent variables: use of cooling shirt, vitamin use, presence of hypertension, and alcohol use. There were six dependent variables on which the ANOVAs were done: SORP, cORP, dBP, sBP, body temperature, and heart rate. Each dependent variable was analyzed four times, once for each independent variable. The main effect of pre/post-race on the dependent variables was only reported for the use of cooling shirts, which was the first independent variable that underwent statistical analysis. Main effects of each independent variable and interaction effects with the repeated measures variable for each dependent variable were reported for each 2-way mixed model ANOVA.

Simple Pearson's r moment correlations were run between postrace ORP measures and continuous variables: age, height, weight, BMI, race years, cockpit temperature, and speed. Using variables that had a significant correlation or had a significant pre-post response in the 2-way ANOVAs, a forward stepwise multiple regression analysis, with a $P$ to enter of 0.05 and a $P$ to remove of 0.15 , was done to determine if there were specific variables that could predict post-race redox status.

All data are presented as mean + standard error of the mean (SEM). The inverse of the cORP data was used to make it relevant with previous studies that found it was not often normally distributed $[4,5]$. cORP data is presented as icORP $\left(\mu \mathrm{C}^{-1}\right)$; higher icORP values are suggestive of lower antioxidant capacity.

\section{Results}

Baseline data was obtained for 26 drivers; post-race data was available for 23 drivers. Descriptive statistics are in $>$ Table 1. Drivers ranged from 36 to 76 years old with 1 to 45 years of driving experience. Drivers were healthy with a BMI range of 20.8-30.0. Age was correlated to race years $(r=0.54)$ and car speed $(r=-0.47)$. Older drivers tended to have more experience, and as age increased, maximum lap speed decreased. Heart rate, blood pressure, body temperature, sORP, and icORP were not changed due to age, car speed, years racing, or car temperature (correlation r values are presented in $>$ Table 2 ).

The main effect of racing (pre vs. post) was significant for several physiological measures. There was an increase in SORP postrace compared to baseline (main effect: $F(1,20)=26.4, P<0.004$; 
- Table 2 Increasing weight was correlated with increased sORP and icORP values after racing.

\begin{tabular}{|c|c|c|c|c|c|c|c|c|}
\hline & & Age & Height & Weight & BMI & Race Years & Cockpit Temp. & Speed \\
\hline \multirow[t]{2}{*}{ Heart Rate (beats/min) } & Baseline & 0.08 & 0.07 & 0.16 & 0.25 & 0.02 & -0.14 & -0.34 \\
\hline & Post-race & 0.10 & 0.19 & 0.11 & 0.03 & -0.03 & -0.15 & -0.34 \\
\hline \multirow[t]{2}{*}{$\mathrm{sBP}(\mathrm{mm} \mathrm{Hg})$} & Baseline & 0.30 & 0.41 & 0.35 & 0.18 & 0.13 & -0.19 & -0.26 \\
\hline & Post-race & 0.07 & -0.08 & -0.31 & -0.31 & 0.11 & -0.16 & -0.07 \\
\hline \multirow[t]{2}{*}{$\mathrm{dBP}(\mathrm{mm} \mathrm{Hg})$} & Baseline & -0.26 & -0.03 & 0.01 & 0.08 & -0.23 & 0.20 & 0.04 \\
\hline & Post-race & -0.07 & -0.13 & -0.38 & -0.36 & -0.23 & 0.19 & 0.19 \\
\hline \multirow[t]{2}{*}{ Body Temp $\left({ }^{\circ} \mathrm{C}\right)$} & Baseline & -0.35 & -0.03 & -0.12 & 0.01 & -0.06 & 0.31 & 0.14 \\
\hline & Post-race & -0.08 & 0.39 & 0.25 & 0.04 & -0.09 & 0.10 & 0.04 \\
\hline \multirow[t]{2}{*}{ sORP (mV) } & Baseline & -0.02 & -0.03 & -0.06 & -0.14 & -0.35 & 0.15 & -0.12 \\
\hline & Post-race & 0.02 & 0.37 & $0.45^{*}$ & 0.32 & -0.17 & 0.11 & -0.06 \\
\hline \multirow[t]{2}{*}{ icORP $\left(\mu C^{-1}\right)$} & Baseline & 0.04 & 0.14 & 0.20 & 0.10 & -0.39 & 0.03 & -0.10 \\
\hline & Post-race & 0.00 & 0.27 & $0.42^{*}$ & 0.33 & -0.34 & 0.22 & -0.02 \\
\hline
\end{tabular}

No other physiological measure was affected by either driver demographics or racing conditions. Values presented are correlation $r$ values, ${ }^{*} \mathrm{p}<0.05$

Fig. 2a). On average, drivers had a $14.6 \%$ increase in sORP after racing, further $84 \%$ of all baseline sORP values were lower than the average post-race sORP values. Body temperature and heart rate also increased post-race (main effects respectively: $F(1,20)=13.9$, $P=0.001$ and $F(1,20)=35.9, P<0.001$; Fig. $2 b, c)$. There were no significant changes after racing on sBP, dBP, or icORP. > Table 3 provides the mean and SEM for these variables. There were no significant interactions between pre/post-race and hypertension, vitamin use, use of cooling shirts, or alcohol use (interaction effects: $P>0.05$ for all, data not shown), indicating that these groupings did not preferentially change the physiological measures post-race.

Group effects were found that were independent of racing. Drivers with hypertension, all of whom were also taking hypertension medication, had lower overall sORP values compared to those that were normotensive (main effect: $F(1,20)=4.40, P=0.048$; $>$ Fig. 3a). Those taking vitamins had higher antioxidant capacity (lower icORP values) compared to those that did not (main effect: $F(1,21)=6.66$, $P=0.02$; Fig. 3 b). Vitamin use tended to reduce sORP values but the effect failed to reach significance (main effect: $F(1,21)=3.97$, $p=0.059)$. Vitamin use did not affect sBP, dBP, or any other physiological measure $(P>0.05$ all, data not shown). Lastly, neither cooling shirts nor alcohol use had a significant effect on heart rate, blood pressure, sORP, or icORP (main effect: $\mathrm{P}>0.05$ all analyses, data not shown).

To explore the relationship between hypertension and vitamin use, an ad hoc analysis was done. A one-way ANOVA was run between hypertension with vitamin use $(n=5)$ and normotensive drivers with and without vitamin use ( $\mathrm{n}=8$ each); only two hypertensive drivers were not using vitamins, thus this group was not included in the analysis but are represented in $>$ Fig. 3 . The analysis suggests that there was a significant decrease in SORP and icORP in hypertensive drivers taking vitamins compared to normotensive drivers not taking vitamins ( $\mathbf{F i g} . \mathbf{3 c}$,d). Normotensive drivers using vitamins had ORP values in between the two groups and were not significantly different from either.

Correlations between continuous variables indicate that drivers' weight, baseline sBP, and baseline icORP were related to higher post-race $\operatorname{sORP}(r=0.45,0.58$, and 0.55 respectively, $\mathrm{P}<0.05)$. Age, height, BMI, cockpit temperature, speed, heart rate, and body temperature failed to correlate with any other physiological measure $(P>0.05$, $>$ Table 2$)$.

To determine which baseline variables might influence post-race sORP, a multiple regression analysis was done using variables that reached significance with post-race sORP during simple correlation analyses (see previous and $>$ Table 2 ) or that themselves had significant pre- and post-race differences ( $\bullet$ Fig. $\mathbf{2 b}, \mathbf{c}$ ). Results revealed that baseline sBP and icORP values significantly and independently changed with post-race SORP values (multiple correlation coefficient $=0.78, P<0.001$; partial correlations: 0.65 for sBP, 0.63 for icORP, $\mathrm{P}<0.05)$. Drivers' weight, body temperature, and heart rate failed to meet inclusion criteria. An XYZ graph was created using the regression equation ( $\triangleright$ Fig. 4 ):

Post-race sORP $=32.2+8.4{ }^{*} i c O R P+0.47^{*} s B P$.

For every $1 \mu \mathrm{C}^{-} 1$ increase in baseline icORP values, a corresponding increase in post-race sORP of $8.4 \mathrm{mV}$ was expected, thus lower antioxidant capacity prior to the race resulted in lower sORP values after the race. For every $10 \mathrm{~mm} \mathrm{Hg}$ increase in sBP before the race, post-race sORP values were estimated to be $4.7 \mathrm{mV}$ higher.

\section{Discussion}

Exercise is known to alter the redox balance [26, 39, 40,43]. This study found that car racing, a unique form of exercise, elevates sORP, a marker of redox balance. The magnitude of the sORP increase after the race was directly related to drivers' pre-race sBP and antioxidant capacity (icORP). Thus, if a driver had a high sBP and a high icORP value before the race, the sORP values after the race tended to be higher. A driver's weight was also related to postrace SORP but not to the extent or predictive value that sBP and icORP values were, most likely because weight correlates strongly with sBP [42]. No other physiological measure or driver characteristic was found to influence post-race sORP values. This is the first study to our knowledge that indicates that race car driving changes the redox balance in favor of OS. Confirming previous work in drivers, we also found elevated heart rate and body temperature in drivers after racing and a lack of change in blood pressure $[8,44,47,49]$. 


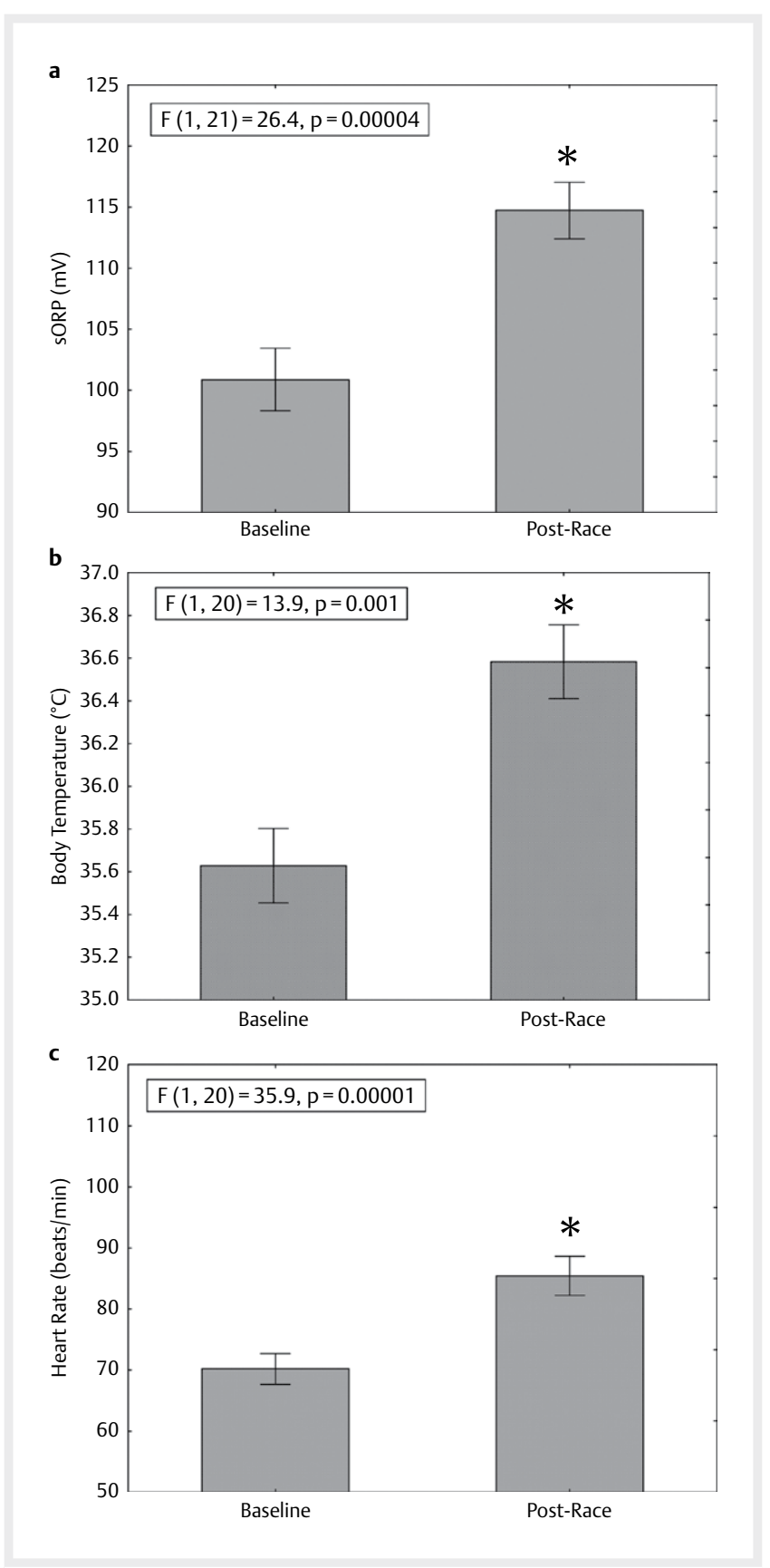

- Fig. 2 Significant elevations in SORP a, body temperature $\mathbf{b}$, and heart rate $\mathbf{c}$ were measured post-race compared to baseline. Respective ANOVA results are presented within each graph. ${ }^{*}$ significant increase over baseline, $\mathrm{P}<0.05$.

The redox imbalance induced by exercise most likely comes from two sources: the production of ROS and NO as modulators of vasoconstriction and dilation respectively $[22,23,34,46]$ and from damage to muscle tissue that prompts an inflammatory response $[1,12,28,31,35]$. With routine exercise, individuals can attenuate the acute oxidative response produced by a single exercise event; furthermore, they can achieve lower resting levels of OS and raise antioxidant reserves $[13,27,50]$. The current data found that drivers with a higher antioxidant capacity (lower icORP value) pre-race, or resting value, had a smaller increase in sORP post-race. Although
- Table 3 Descriptive statistics and P-values between baseline and postrace for icORP, sBP, and $\mathrm{dBP}$.

\begin{tabular}{|c|c|c|c|}
\hline & $\begin{array}{c}\text { Baseline } \\
\text { (mean }+/- \text { SEM) }\end{array}$ & $\begin{array}{c}\text { Post-race } \\
\text { (mean }+/ \text { - SEM) }\end{array}$ & P value \\
\hline icORP $\left(\mu \mathrm{C}^{-} 1\right)$ & $2.20+/-0.15$ & $2.18+/-0.13$ & 0.78 \\
\hline $\mathrm{sBP}(\mathrm{mm} \mathrm{Hg})$ & $132.4+/-2.8$ & $132.0+/-2.5$ & 0.96 \\
\hline $\mathrm{dBP}(\mathrm{mm} \mathrm{Hg})$ & $78.4+/-2.0$ & $77.5+/-2.6$ & 0.45 \\
\hline
\end{tabular}

we did not inquire into drivers' exercise routines, it is possible that those with higher resting antioxidant capacity and lower drivinginduced sORP tended to engage in routine exercise.

Routine exercise also reduces SBP, which was related to lower driving-induced OS. Goon et al. found that daily Tai Chi reduced sBP but had no effect on $\mathrm{dBP}[14]$. Isometric and resistance training also reduced sBP but not dBP [24, 30]. Systolic BP correlates to plasma levels of hydrogen peroxide, an intermediary between hydroxyl radicals and superoxide radicals in the ROS family, whereas $\mathrm{ABP}$ was not [22, 23], supporting our conclusion that sBP, but not $d B P$, is related to increased OS in race car drivers.

Ascorbic acid supplements have been shown to decrease dBP in a time-dependent manner but had little effect on SBP [6]. We found that the vitamin supplement was not related to $\mathrm{dBP}$ or $\mathrm{SBP}$ in this study, but its use did increase antioxidant capacity (icORP). Because vitamin supplements in general include more than just ascorbic acid, the relationship with blood pressure in this study could be overshadowed by other factors, such as routine exercise, which affects both sBP and antioxidant reserves.

Excess weight is associated with increased markers of OS, specifically the production of ROS from white adipose tissue [36]. In the current study, in which BMls suggest the drivers were relatively healthy, weight was still related to race-induced OS, but weight alone could not predict the post-race outcome of sORP. Body temperature and heart rate also correlated, but the multiple regression suggested that they were also poor independent predictors of postrace redox balance.

Independent of racing status, ORP levels also changed as a function of hypertension and/or high blood pressure medication. Drivers with hypertension had overall, reduced sORP levels compared to those that were normotensive; however, every driver with hypertension was on high blood pressure medications. It is suspected that the medication may be the driving force behind the lower sORP values. Hypertension is associated with elevated vascular OS but several studies report direct and indirect antioxidant effects of calcium channel blockers, statins, and angiotensin receptor antagonists, which are often used to treat hypertension $[10,11,16]$. Thus this could be factor behind the lower sORP values we found in this group. We also found that daily vitamin use in conjunction with hypertension medication further reduced sORP and increased antioxidant capacity.

The unique aspects of race car driving are the extreme conditions under which drivers must perform. In the current study, cockpit temperature and speed had no effect on any physiological measure. It is possible that the cockpit temperatures of this particular racing event did not reach levels that would provoke an additional physiological or OS response beyond what simply driving induces. Compared to previous work in which cockpit temperatures reached 

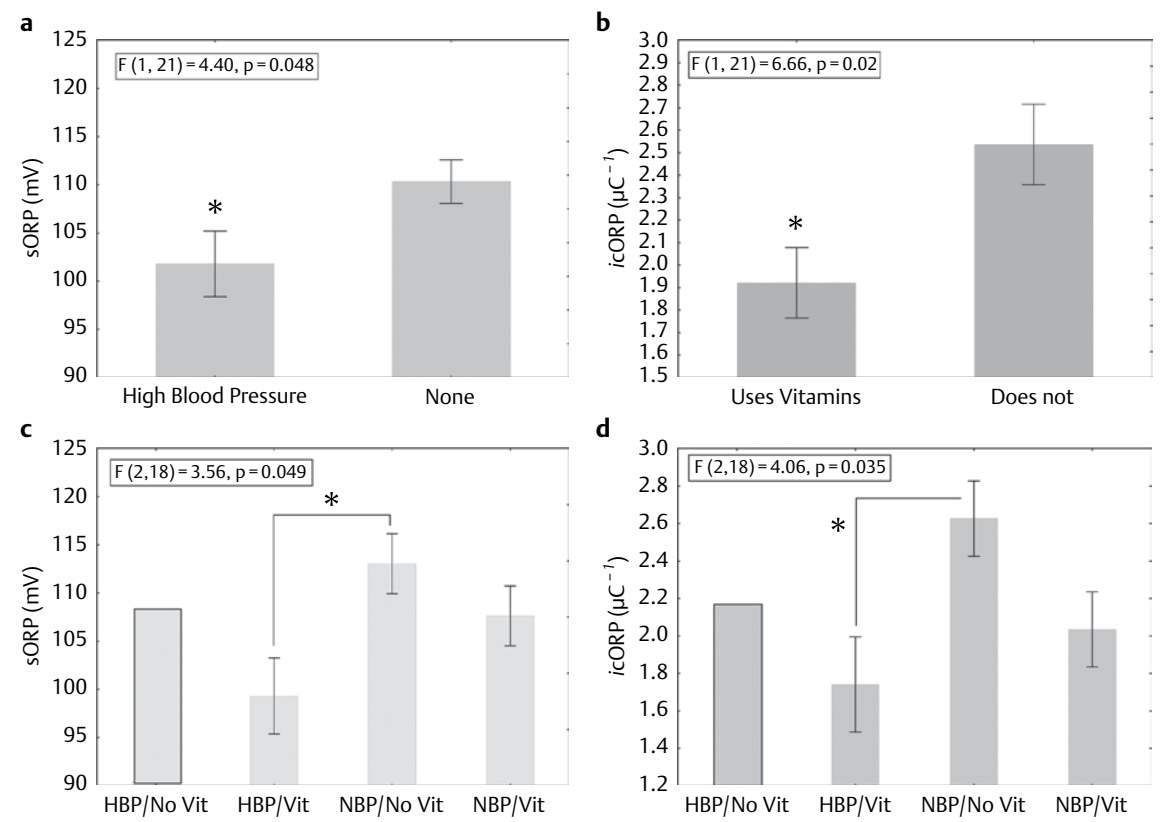

Fig. 3 Group differences independent of racing status. a. Those drivers with hypertension who were taking high blood pressure medication have significantly lower sORP values. All hypertensive drivers were taking medications. $\mathbf{b}$. Those drivers who take vitamins daily had lower icORP values and thus higher antioxidant capacity than those who do not take vitamins. c. Analysis showed hypertensive drivers who take vitamins (HBP/Vit) had significantly lower sORP values than normotensive drivers who do not take vitamins (NBP/No Vit). Normotensive drivers taking vitamins (NBP/Vit) were in between these two values and did not significantly differ from either one. $\mathbf{d}$. icORP values were lower in HBP/Vit compared to the NBP/No Vit. Again, the NPB/Vit had icORP values in between the other two groups. There were only 2 hypertensive drivers who did not take vitamins (HBP/No Vit), so this group was not included in the statistical analysis, but the mean sORP and icORP values are represented in the graphs. Respective ANOVA results are presented within each graph. ${ }^{*}$ Significant difference, $\mathrm{P}<0.05$.

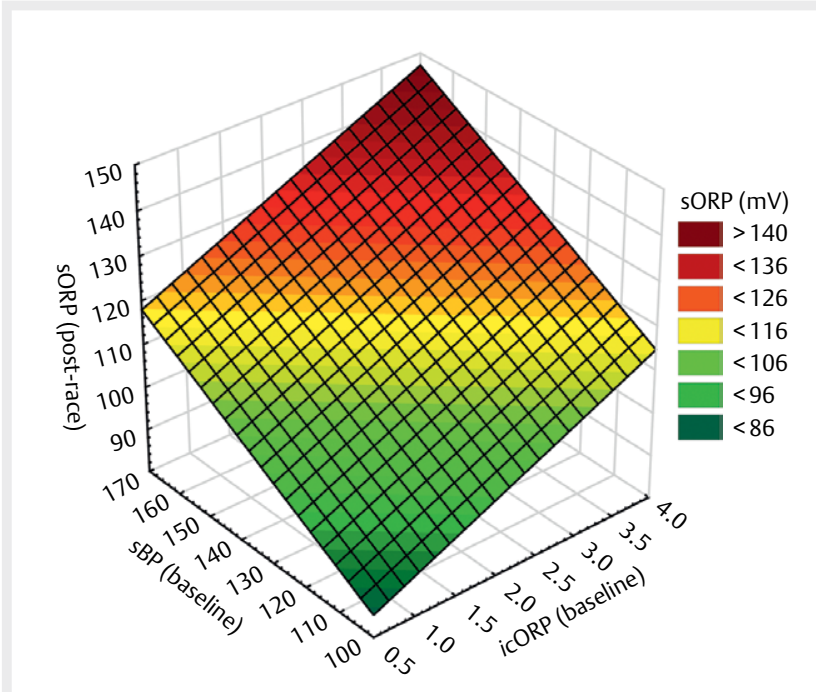

Fig. 4 Post-race sORP values increased when baseline sBP and icORP values were increased. A 3-D XYZ graph plotting the estimated sORP values as a function of SBP and icORP values based on the multiple regression equation $(P<0.05$, see main text). Color legend represents the corresponding post-race sORP values, with red indicating higher sORP values and green indicating lower sORP values. upwards of $66^{\circ} \mathrm{C}[8]$, the current study had cockpit temperatures ranging from $22-37^{\circ} \mathrm{C}$. Because of the temperate conditions, the use of cooling shirts was unnecessary and as such, we found no effect of cooling shirts on any measure either. In fact, none of the physiological measures were affected by driver demographics or driving conditions.

\section{Conclusions}

This study is the first, to our knowledge, to report increased OS markers after high-speed car racing. Like other forms of exercise, car racing increased heart rate and body temperature. Blood pressure remained unchanged, however higher baseline sBP was predictive of greater post-race elevations in SORP. Baseline antioxidant capacity (icORP) also projected post-race sORP. Drivers with lower sBP or higher antioxidant capacity prior to racing had substantially small changes in redox balance after the race. Based on previous research, it could be suggested that race car drivers engage in routine exercise between races to lower SBP and raise antioxidant capacity. Although this study is based on a small number of drivers, it contributes to the limited collection of studies in driver science trying to elucidate the physiological and, in the current study, redox changes that result from racing with the hope of increasing the ability to evaluate and reduce risk in the sport of car racing. 


\section{Acknowledgements}

The authors gratefully acknowledge the assistance of Ingrid Ingham, Diana Redmond, Youri Kim, Devin Walters, Steven Pekarek, and Jerome Dyck. Special thanks are extended to the staff at High Plains Raceway (Deer Trail, CO) and the participating drivers from the Porsche Club of America (PCA) Rocky Mountain Region's 24th Porsche Club Race.

\section{Conflict of Interest}

Dr. Bjugstad was a paid employee and Dr. Bar-Or was a paid consultant for Aytu BioScience, Inc. Dr Gutowski is a member of the Porsche Club of America. The remaining co-authors declare that they have no competing interests.

\section{References}

[1] Barbas I, Fatouros IG, Douroudos II, Chatzinikolaou A, Michailidis Y, Draganidis D, Jamurtas AZ, Nikolaidis MG, Parotsidis C, Theodorou AA, Katrabasas I, Margonis K, Papassotiriou I, Taxildaris K. Physiological and performance adaptations of elite Greco-Roman wrestlers during a one-day tournament. Eur J Appl Physiol 2011; 111: 1421-1436

[2] Bielli A, Scioli MG, Mazzaglia D, Doldo E, Orlandi A. Antioxidants and vascular health. Life Sci 2015; 143: 209-216

[3] Bigarella CL, Liang R, Ghaffari S. Stem cells and the impact of ROS signaling. Development 2014; 141: 4206-4218

[4] Bjugstad KB, Fanale C, Wagner J, Jensen J, Salottolo K, Rael LT, Bar-Or D. A $24 \mathrm{~h}$ delay in the redox response distinguishes the most severe stroke patients from less severe stroke patients. J Neurol Neurophysiol 2016; 7: 10

[5] Bjugstad KB, Rael LT, Levy S, Carrick M, Mains CW, Slone DS, Bar-Or D. Oxidation-reduction potential as a biomarker for severity and acute outcome in traumatic brain injury. Oxid Med Cell Longev 2016; 2016: 6974257

[6] Block G, Mangels AR, Norkus EP, Patterson BH, Levander OA, Taylor PR. Ascorbic acid status and subsequent diastolic and systolic blood pressure. Hypertension 2001; 37: 261-267

[7] Bobe G, Cobb TJ, Leonard SW, Aponso S, Bahro CB, Koley D, Mah E, Bruno RS, Traber MG. Increased static and decreased capacity oxidation-reduction potentials in plasma are predictive of metabolic syndrome. Redox Biol 2017; 12: 121-128

[8] Carlson LA, Ferguson DP, Kenefick RW. Physiological strain of stock car drivers during competitive racing. J Therm Biol 2014; 44: 20-26

[9] Cobley JN, McHardy H, Morton JP, Nikolaidis MG, Close GL. Influence of vitamin $C$ and vitamin $\mathrm{E}$ on redox signaling: Implications for exercise adaptations. Free Radic Biol Med 2015; 84: 65-76

[10] Davignon J. Beneficial cardiovascular pleiotropic effects of statins. Circulation 2004; 109: III39-III43

[11] Derosa G, Mugellini A, Pesce RM, D'Angelo A, Maffioli P. Olmesartan combined with amlodipine on oxidative stress parameters in Type 2 Diabetics, compared with single therapies: A randomized, controlled, clinical trial. Medicine (Baltimore) 2016; 95: e3084

[12] Fatouros IG, Chatzinikolaou A, Douroudos II, Nikolaidis MG, Kyparos A, Margonis K, Michailidis Y, Vantarakis A, Taxildaris K, Katrabasas I, Mandalidis D, Kouretas D, Jamurtas AZ. Time-course of changes in OS and antioxidant status responses following a soccer game. J Strength Cond Res 2010; 24: 3278-3286
[13] Fatouros IG, Jamurtas AZ, Villiotou V, Pouliopoulou S, Fotinakis P, Taxildaris K, Deliconstantinos G. OS responses in older men during endurance training and detraining. Med Sci Sports Exerc 2004; 36: 2065-2072

[14] Goon JA, Aini AH, Musalmah M, Anum MY, Nazaimoon WM, Ngah WZ. Effect of Tai Chi exercise on DNA damage, antioxidant enzymes, and OS in middle-age adults. J Phys Act Health 2009; 6: 43-54

[15] Gray SP, Jandeleit-Dahm KA. The role of NADPH oxidase in vascular disease - hypertension, atherosclerosis \& stroke. Curr Pharm Des 2015 http://www.ncbi.nlm.nih.gov/pubmed/26510435

[16] Guimaraes DA, Rizzi E, Ceron CS, Martins-Oliveira A, Gerlach RF, Shiva $S$, Tanus-Santos JE. Atorvastatin and sildenafil decrease vascular TGF-beta levels and MMP-2 activity and ameliorate arterial remodeling in a model of renovascular hypertension. Redox Biol 2015; 6: 386-395

[17] Harriss DJ, Atkinson G. Ethical standards in sport and exercise science research: 2016 update. Int J Sports Med 2015; 36: 1121-1124

[18] Hirayama A, Okamoto T, Kimura S, Nagano Y, Matsui H, Tomita T, Oowada S, Aoyagi K. Kangen-karyu raises surface body temperature through OS modification. J Clin Biochem Nutr 2016; 58: 167-173

[19] Jiang T, Sun Q, Chen S. OS: A major pathogenesis and potential therapeutic target of antioxidative agents in Parkinson's disease and Alzheimer's disease. Prog Neurobiol 2016; 147: 1-19

[20] Kandola K, Bowman A, Birch-Machin MA. OS-a key emerging impact factor in health, ageing, lifestyle and aesthetics. Int J Cosmet Sci 2015; 37: (Suppl 2): 1-8

[21] Kim JY, Kawabori M, Yenari MA. Innate inflammatory responses in stroke: Mechanisms and potential therapeutic targets. Curr Med Chem 2014; 21: 2076-2097

[22] Lacy F, Kailasam MT, O'Connor DT, Schmid-Schonbein GW, Parmer R] Plasma hydrogen peroxide production in human essential hypertension: Role of heredity, gender, and ethnicity. Hypertension 2000; 36 : 878-884

[23] Lacy F, O'Connor DT, Schmid-Schonbein GW. Plasma hydrogen peroxide production in hypertensives and normotensive subjects at genetic risk of hypertension. Journal of hypertension 1998; 16 : 291-303

[24] Lemes IR, Ferreira PH, Linares SN, Machado AF, Pastre CM, Netto J]. Resistance training reduces systolic blood pressure in metabolic syndrome: a systematic review and meta-analysis of randomised controlled trials. Br J Sports Med 2016, doi:10.1136/bjsports-2015-094715

[25] Margaritelis NV, Veskoukis AS, Paschalis V, Vrabas IS, Dipla K, Zafeiridis A, Kyparos A, Nikolaidis MG. Blood reflects tissue oxidative stress: A systematic review. Biomarkers 2015; 20: 97-108

[26] McAnulty SR, McAnulty L, Pascoe DD, Gropper SS, Keith RE, Morrow JD, Gladden LB. Hyperthermia increases exercise-induced OS. Int J Sports Med 2005; 26: 188-192

[27] Miyazaki H, Oh-ishi S, Ookawara T, Kizaki T, Toshinai K, Ha S, Haga S, Ji $\mathrm{LL}$, Ohno $\mathrm{H}$. Strenuous endurance training in humans reduces OS following exhausting exercise. Eur J Appl Physiol 2001; 84: 1-6

[28] Nikolaidis MG, Kyparos A, Spanou C, Paschalis V, Theodorou AA, Vrabas IS. Redox biology of exercise: An integrative and comparative consideration of some overlooked issues. J Exp Biol 2012; 215: $1615-1625$

[29] OHara K, Inoue Y, Sumi Y, Morikawa M, Masuda S, Okamoto K, Tanaka $\mathrm{H}$. Oxidative stress and heart rate variability in patients with vertigo. Acute Medicine \& Surgery 2015; 2: 163-168

[30] Peters PG, Alessio HM, Hagerman AE, Ashton T, Nagy S, Wiley RL. Short-term isometric exercise reduces systolic blood pressure in hypertensive adults: possible role of reactive oxygen species. Int J Cardiol 2006; 110: 199-205 
[31] Raastad T, Owe SG, Paulsen G, Enns D, Overgaard K, Crameri R, Kiil S, Belcastro A, Bergersen L, Hallen J. Changes in calpain activity, muscle structure, and function after eccentric exercise. Med Sci Sports Exerc 2010; 42: 86-95

[32] Rael LT, Bar-Or R, Kelly MT, Carrick MM, Bar-Or D. Assessment of OS in patients with an isolated traumatic brain injury using disposable electrochemical test strips. Electroanalysis 2015; 27: 2567-2573

[33] Rael LT, Bar-Or R, Mains CW, Slone DS, Levy AS, Bar-Or D. Plasma oxidation-reduction potential and protein oxidation in traumatic brain injury. J Neurotrauma 2009; 26: 1203-1211

[34] Rodrigo R, Gonzalez J, Paoletto F. The role of OS in the pathophysiology of hypertension. Hypertens Res 2011; 34: 431-440

[35] Sakelliou A, Fatouros IG, Athanailidis I, Tsoukas D, Chatzinikolaou A, Draganidis D, Jamurtas AZ, Liacos C, Papassotiriou I, Mandalidis D, Stamatelopoulos K, Dimopoulos MA, Mitrakou A. Evidence of a redox-dependent regulation of immune responses to exercise-induced inflammation. Oxid Med Cell Longev 2016; 2016: 2840643

[36] Sakurai T, Ogasawara J, Shirato K, Izawa T, Oh-Ishi S, Ishibashi Y, Radak $\mathrm{Z}$, Ohno H, Kizaki T. Exercise training attenuates the dysregulated expression of adipokines and OS in white adipose tissue. Oxid Med Cell Longev 2017; 2017: 9410954

[37] Shapiro HM. Redox balance in the body: An approach to quantitation. Journal of Surgical Research 1972; 13: 138-152

[38] Shirley R, Ord EN, Work LM. Oxidative stress and the use of antioxidants in stroke. Antioxidants (Basel) 2014; 3: 472-501

[39] Souza-Silva AA, Moreira E, de Melo-Marins D, Scholer CM, de Bittencourt PI Jr, Laitano O. High intensity interval training in the heat enhances exercise-induced lipid peroxidation, but prevents protein oxidation in physically active men. Temperature (Austin) 2016; 3: 167-175

[40] Spanidis Y, Goutzourelas N, Stagos D, Mpesios A, Priftis A, Bar-Or D, Spandidos DA, Tsatsakis AM, Leon G, Kouretas D. Variations in OS markers in elite basketball players at the beginning and end of a season. Exp Ther Med 2016; 11: 147-153
[41] Spanidis Y, Mpesios A, Stagos D, Goutzourelas N, Bar-Or D, Karapetsa M, Zakynthinos E, Spandidos DA, Tsatsakis AM, Leon G, Kouretas D. Assessment of the redox status in patients with metabolic syndrome and type 2 diabetes reveals great variations. Exp Ther Med 2016; 11: 895-903

[42] Staessen J, Fagard R, Amery A. The relationship between body weight and blood pressure. J Hum Hypertens 1988; 2: 207-217

[43] Stagos D, Goutzourelas N, Bar-Or D, Ntontou AM, Bella E, Becker AT, Statiri A, Kafantaris I, Kouretas D. Application of a new oxidationreduction potential assessment method in strenuous exercise-induced OS. Redox Rep 2015; 20: 154-162

[44] Taggart P, Gibbons D, Somerville W. Some effects of motor-car driving on the normal and abnormal heart. Br Med J 1969; 4: 130-134

[45] Tostes RC, Carneiro FS, Carvalho MH, Reckelhoff JF. Reactive oxygen species: Players in the cardiovascular effects of testosterone. Am J Physiol Regul Integr Comp Physiol 2016; 310: R1-14

[46] Touyz RM, Briones AM. Reactive oxygen species and vascular biology: implications in human hypertension. Hypertens Res 2011; 34: 5-14

[47] Walker SM, Dawson B, Ackland TR. Performance enhancement in rally car drivers via heat acclimation and race simulation. Comp Biochem Physiol A Mol Integr Physiol 2001; 128: 701-707

[48] Watkins ES. The physiology and pathology of formula one Grand Prix motor racing. Clin Neurosurg 2006; 53: 145-152

[49] Yanagida R, Takahashi K, Miura M, Nomura M, Ogawa Y, Aoki K, Iwasaki KI. Speed ratio but cabin temperature positively correlated with increased heart rates among professional drivers during car races. Environ Health Prev Med 2016, doi:10.1007/s12199-016-0544-0

[50] Zalavras A, Fatouros IG, Deli CK, Draganidis D, Theodorou AA, Soulas $\mathrm{D}$, Koutsioras $\mathrm{Y}$, Koutedakis $\mathrm{Y}$, Jamurtas AZ. Age-related responses in circulating markers of redox status in healthy adolescents and adults during the course of a training macrocycle. Oxid Med Cell Longev 2015; 2015: 283921

[51] Zhi L, Hu X, Han C. Biphasic changes (overreduction and overoxidation) of plasma redox status and clinical implications in early stage of severe burns. J Crit Care 2014; 29: 1063-1068 